RESEARCH ARTICLE

\title{
Estimating Population Growth Rates and Instantaneous Population from Periodized Settlement Data
}

\author{
Keith W. Kintigh and Matthew A. Peeples
}

Settlement surveys that yield counts of the number of houses or rooms dated to a chronological period can be used to indicate population and to estimate rates of population growth or decline. Population estimates and population growth rates are, of course, interpretively critical for describing and explaining many aspects of social dynamics. For this sort of survey data, population growth rates can be estimated by applying an ordinary, compound interest formula to room counts, standardized by period length, for successive time periods. This article offers a more nuanced approach that simulates a continuous process of room construction and abandonment, yielding a total number of rooms occupied during a period. The modeled growth rate is the value at which the model total most closely matches the value observed in the settlement data, given the set of model parameters. The model results are sensitive to both structure use-life and the founding room count. This sensitivity does not reflect a defect of the model. Instead it points to a major problem of equifinality-a great variety of different processes could account for the observed data. Exploration of three cases shows that reviewing the model results for a range of combinations of reasonable parameter values can provide demographic insights that are more informative-and can be markedly different-than those provided by the standard formula.

Keywords: Demography; Population Growth; Settlement Survey; Simulation; Southwest USA

\section{Introduction}

Accurate demographic reconstructions are critical for addressing issues of considerable importance. To name a few, these include assessing prehistoric migration and population circulation, arguments that involve resource availability or carrying capacity, and for identifying and explaining major settlement pattern transformations such as episodes of population aggregation or nucleation. Demographic reconstructions from archaeological data are often based on settlement pattern data conveyed by some aggregate population-related indicator, e.g., house count, or area covered by structures, separated into archaeologically identifiable periods that are often longer than we would like. Thus, our task is to extract the best possible demographic information from the untidy archaeological record (Drennan, Berrey and Peterson 2015).

At a minimum, we'd like to be confident in our understanding of the relative trends, that growth in one period is faster or slower than another. In terms of the absolute values of growth rates, it is important to know, in particular, whether the rate of growth is too high to be accounted for by in-place growth, a level that Cowgill (1975: 511)

Arizona State University, US

Corresponding author: Keith W. Kintigh (KINTIGH@ASU.edu) estimates at 0.6 to $0.7 \%$. Rates higher than that threshold for extended periods are taken to indicate in-migration.

\section{Assumptions and Scope}

In this article we consider cases in which systematic survey produces estimates of house counts assigned to a series of reasonably well-dated chronological periods but with no temporal resolution within periods. In different areas and time periods, houses could include separate residential structures, e.g., as indicated by house mounds, pit structure depressions, tipi rings, etc., or they could be portions of larger residential buildings (see Flannery 2002; Ortman, Varien and Gripp 2007; Schacht 1981; Schreiber and Kintigh 1996; Steadman 2006; Willey 1956; Wilshusen 2002 for a range of examples). We assume that there is relatively high residential mobility and/or that structures have a limited use-life, e.g., because of wood decay or insect infestation, after which they are abandoned rather than repaired indefinitely. Because of the limited use-life or other reasons driving residential mobility, we assume that structures are generally occupied for a considerably shorter time than the lengths of the chronological periods used, though we assume that individual structures may span period boundaries. We further assume that the human population is in approximately constant proportion to the counts of occupied rooms or houses. While we do not need to know the particular ratio to estimate 
growth rates, we of course do need it to estimate absolute population. Finally, we assume that there is continuity of occupation throughout the period under consideration. A hiatus and reoccupation occurring within a period cannot be seen in the methods discussed here.

With rare exceptions, these conditions obtain over much of the northern Southwest USA from about AD 800 to 1400 . Our main examples come from the Cíbola or Zuni region in the Southwest. There, after AD 800, the dominant architectural form was the "pueblo," with contiguous, rectangular masonry- or adobe-walled surface rooms (Figure 1). Archaeologically, it is frequently possible to count or reliably estimate the number of rooms in a site from surface evidence. Cultural continuity with historic and contemporary descendant people, as well as architectural and artifactual evidence make clear that households are made up of suites of contiguous rooms, often including living, cooking, and storage rooms. With rare exceptions, these pueblo rooms are all used for human habitation. Until about AD 1300 most ceremonial rooms are subterranean and round and therefore easily distinguishable.

Ethnographic and experimental evidence indicate limited use lives for these wood, mat, and dirt-roofed structures (see Mindeleff 1891; Cameron 1999; James 1997).
Even though the roofs - the least durable parts of these buildings - were sometimes repaired, room use for more than a generation appears rare because the sites were rarely occupied longer than that. Tree-ring dating of architectural elements, fine grained ceramic chronologies, and accumulation studies indicate that high levels of residential mobility (a generation or less) are characteristic until a major reorganization that occurred at about AD1375 (Thompson 2012; Varien and Mills 1997). For the examples presented here there is no evidence to suggest a hiatus in occupation during the periods discussed. While there is doubtless variability in the number of rooms per household and in the number of people in a household, in the aggregate we can assume that there is a relatively stable ratio of rooms to population. As a result, counts of rooms serve as a better population proxy than counts of households because we can directly estimate room counts based on surface evidence.

As our initial example, we use our 1990-1991 full coverage survey of $10.4 \mathrm{~km}^{2}$ surrounding the prehistoric Zuni settlement of Heshotauthla on the Zuni Indian Reservation in west-central New Mexico. The area was densely occupied, with 305 prehistoric and historic sites, not all of which were occupation sites, recorded in this reasonably small area. A ceramic seriation (Kintigh, Glowacki

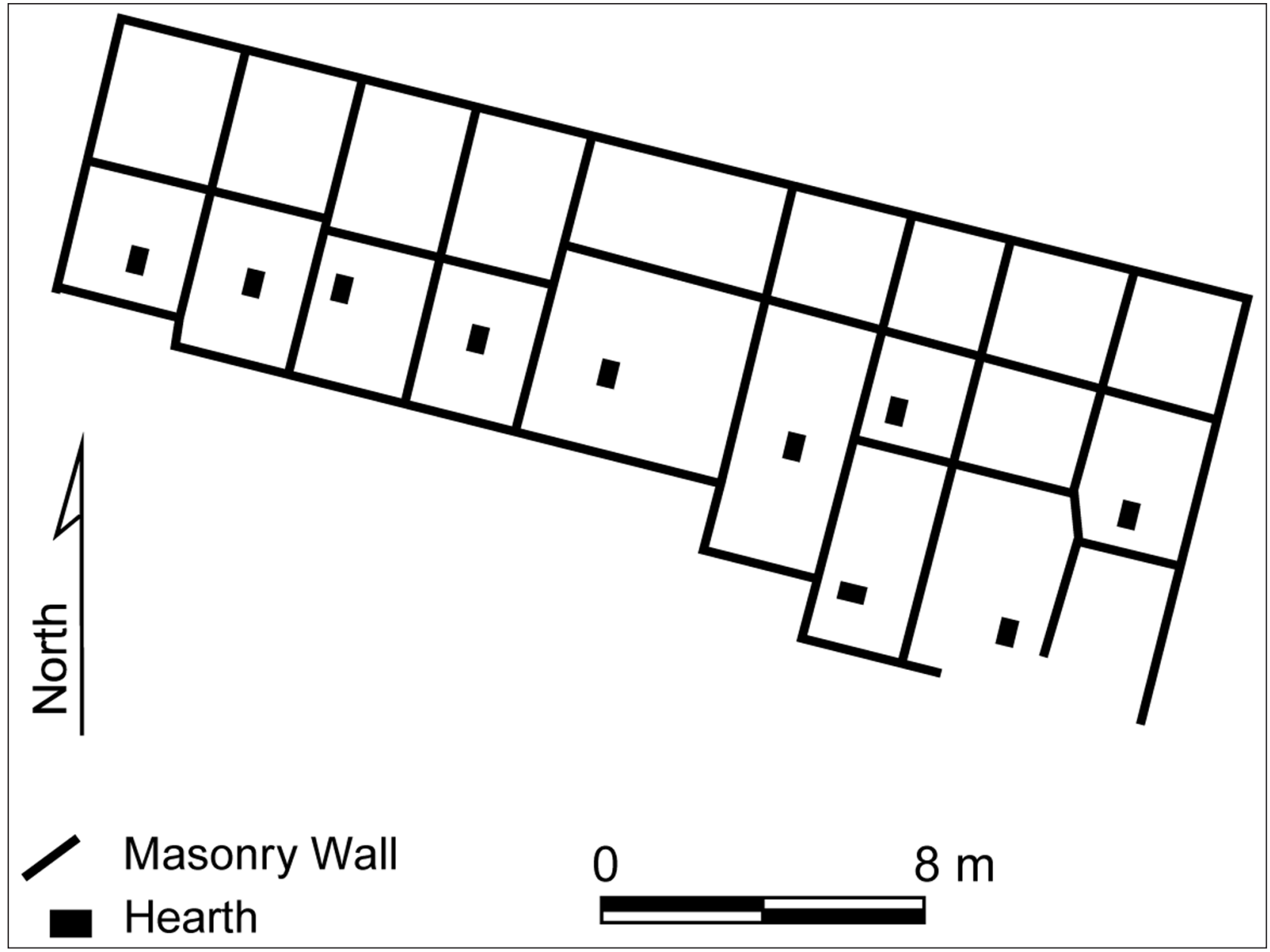

Figure 1: Plan of a typical pueblo room block from the Cíbola region (Techado Springs Pueblo, Roomblock A). Note the consistent layout with living rooms with hearths in the front (south) and storage and other activity rooms in the back (after Peeples 2018: Figure 6.6). 
and Huntley 2004) divided the temporal assignments of the prehistoric occupation sites into 7 periods, between $\mathrm{AD} 850$ and 1275, based on ceramic type complexes (Table 1). While some sites undoubtedly transcend period boundaries, the evidence suggests that the site occupations throughout this long interval are typically short-on the order of a generation or less.

\section{The Compound Interest Approach}

To estimate population growth rates in situations satisfying the assumptions detailed above, we must address the problem of what Ammerman (1981: 77-78) calls "overestimated maps". We cannot assume that all sites dated to a time period were occupied throughout that time period. One solution to the problem is to standardize the room or house counts according to the length of the period (Blake, LeBlanc and Minnis 1986: 452). Standardization is necessary because if structures typically last on the order of 25 years we would expect a 200-year long period to have roughly twice as many rooms as a 100-year long period under conditions of no population growth or decline. Clearly, if the evidence indicates that all rooms dated to a period were occupied for the full period then we would not want to standardize the room counts.

Standardization can be done by dividing the number of rooms by the period length or, more intuitively, by the number of use-lives, or by the number of 25- or 50-year intervals in a given period. In our first example, shown in Table 1, periods range from 50 to 100 years in length. In the final column, we standardize the room counts by dividing the total number of rooms by the number of 25-year intervals in the period. While 25 years is likely in the neighborhood of the structure use-life in our Southwestern cases, the selection of 25 years is not essential to the estimation of the growth rate. However, it does seem to us easier to think about Period C having ' 26 rooms per 25 years' than it is, equivalently, to talk about 1.05 rooms per year.

The compound interest approach uses a simple model of population growth, calculated using a formula applied to the standardized room counts from two, temporally adjacent periods (see also Chamberlain 2006: 19-24; Cowgill 1975; Hill et al. 2004). The relevant formula ${ }^{1}$ is

$$
p_{2}=p_{1}(1+r)^{y}
$$

Table 1: Heshotauthla survey, room counts by period.

\begin{tabular}{lrrrr} 
Period & \multicolumn{1}{c}{ Dates } & Sites & Rooms & Rooms/25 Years \\
\hline A & $850-900$ & 2 & 12 & 6.00 \\
B & $900-950$ & 9 & 38 & 19.00 \\
C & $950-1050$ & 19 & 105 & 26.25 \\
D & $1050-1125$ & 8 & 97 & 32.33 \\
E & $1125-1175$ & 11 & 129 & 64.50 \\
F & $1175-1225$ & 18 & 323 & 161.50 \\
G & $1225-1275$ & 22 & 468 & 234.00
\end{tabular}

which can be rewritten as

$$
\Gamma_{12}=\left(p_{2} / p_{1}\right)^{1 / y}-1
$$

where $p_{1}$ and $p_{2}$ are standardized room counts from the given and subsequent period, $y$ is the number of years between the estimates, and $r$ is the growth rate. In this calculation, growth is assumed to be constant. As presented here, the $r$ values are multiplied by 100 to yield growth rates in percent. To apply this formula, we consider $y$ to be the number of years from the midpoint of the given period to the midpoint of the subsequent period. For example, as the midpoint of period $\mathrm{D}$ is 1087.5 and for period $\mathrm{E}$ it is $1150, y_{D E}$ is 62.5 . The growth rate from period $\mathrm{D}$ to Period $\mathrm{E}$ in Table $\mathbf{1}$ is then calculated as follows:

$$
r_{D E}=100\left[(64.5 / 32.33)^{1 / 62.5}-1\right]=1.14
$$

In effect, $r$ indicates growth from a sort of average population of one period to the average population of the next. That is, the standardized population at one period's midpoint, growing at the rate of $r \%$ per year, will result in the standardized population at the subsequent period's midpoint. The calculated growth rates between all adjacent periods for the Heshotauthla area are provided in Table 2.

It is important to recognize that the calculation does not depend on standardizing using a 25 year basis. To see this, note that the relevant term in the equation is $p_{2} / p_{1}$. Standardizing on a 25 year basis yields $64.5 / 32.33=1.99$ for that term. Had we standardized on an annual basis, dividing by 50 and 75 respectively rather than by 2 and 3 intervals of 25 years, the term would be $2.58 / 1.29=1.99$ and the estimated growth rate is unchanged.

One should be skeptical especially of the calculated A-B growth rate. In the survey area there is no indication of any occupation prior to Period A. This implies that there was an initial migration at some time during period $\mathrm{A}$, but we have no evidence to suggest when that occurred. The calculated rate $(2.3 \%)$ assumes that the initial migration was at the beginning of the period. If it occurred late in period A, for example at AD 890, then y is diminished to 30 years and the calculated rate increases dramatically (to $3.9 \%)$. For this reason, we do not use the period A estimates below.

Table 2: Period-to-period growth rate using compound interest formula.

\begin{tabular}{lrrrrr} 
Interval & Years y & $\mathbf{p}_{1}$ & $\mathbf{p}_{2}$ & $\begin{array}{c}\text { Growth } \\
\text { Rate r (\%) }\end{array}$ \\
\hline A-B & $875-925$ & 50 & 6 & 19 & 2.3 \\
B-C & $925-1000$ & 75 & 19 & 26.25 & 0.4 \\
C-D & $1000-1087.5$ & 87.5 & 26.25 & 32.33 & 0.2 \\
D-E & $1087.5-1150$ & 62.5 & 32.33 & 64.5 & 1.1 \\
E-F & $1150-1200$ & 50 & 64.5 & 161.5 & 1.9 \\
F-G & $1200-1250$ & 50 & 161.5 & 234 & 0.7
\end{tabular}


If we have accurate momentary population estimates at time 1 and time 2 then calculating $r$ in this way provides the constant growth rate, $r$, such that $p 1$ increases to $p 2$ in $y$ years. With contemporary data, we ordinarily have reasonably accurate momentary population values. The U.S. Census, for example, provides a population figure by census tract every 10 years. Calculating the annual growth rate using this formula gives us the constant annual growth rate that, applied to the observed value in the initial census year, yields the observed value 10 years later. Of course, this does not mean that the growth rate was actually constant over the decade. However, it does give us an aggregate sense of what happened over those 10 years expressed in units (percent growth) that can be compared to other times and places.

Contrast the contemporary example with the typical archaeological situation. We almost never have indicators that allow us to estimate momentary populations, instead we have cumulative counts of structures (our population indicators) accumulated over the course of period. While these counts are standardized, as described above, it is not at all obvious that the standardized value is an appropriate stand-in for the momentary population at the midpoint of a period, as is assumed in this approach.

\section{Alternative Approach: Modeling Structure Construction and Abandonment}

By making a few more assumptions and simulating the process of room construction and abandonment, we can estimate growth rates and, in addition, get estimates of the momentary population or rooms at any point in time. This approach yields estimates of population growth or decline within periods, rather than from one period to the next as in the compound interest approach (see Dewar 1991; Kintigh 1994; Petrie and Lynum 2020; Ortman 2016; Mills et al. 2018 for alternative approaches to modeling settlement contemporaneity for periodized data).

As in the compound interest approach, we need to know each period's length and the total room count dated to each period. We assume that the growth rate we are attempting to estimate is constant, though unknown, within a period rather than constant between period midpoints, as assumed in the compound interest approach. We need to assume a structure use-life and to have a non-zero estimate of the starting room count at the beginning of the initial period of the sequence. The beginning room counts for all other periods are generated by the simulation.

Starting with the number of rooms occupied at the beginning of a given period, each year it simulates the abandonment of rooms that have reached their use-life and the construction of replacement rooms and, in addition, the construction of new rooms or abandonment of occupied rooms as dictated by the application of a constant growth rate. Thus, for a given growth rate, the simulation produces a cumulative number of rooms that have a majority of their occupation dated to that period. The objective, for each period, is to find the growth rate for which the simulated cumulative number of rooms dated to that period that matches the observed cumulative number of rooms for that same period. This is accomplished by running the simulation for a range of growth rates and finding the rate that yields the observed number of rooms for that period.

Ignoring, for now, some of the messy details, running the simulation for the Heshotauthla survey produces the results presented in Table $\mathbf{3}$ and graphed in comparison with the traditional approach in Figure 2. The differences in calculated growth rates between the approaches is illuminating. Most interestingly, the simulation approach shows both a much higher growth rate about AD 1150 to 1175 and it shows a substantial decline (negative growth rate) at the end of the sequence where the formula still shows a substantial increase. The high growth rates from 1125 to 1225 result in a high starting number of rooms (208) in the final, 1225-1275 period. Simple replacement of the rooms over this period (i.e., zero growth) would result in more cumulative rooms dated to that period than are observed. This terminal period decline makes archaeological sense because the very large (800+ rooms) protohistoric pueblo of Heshotauthla just outside the survey area began siphoning off population from the survey area late in the 1225-1275 Period.

\section{Operation of the Simulation}

The initial period begins with a user-stipulated number of rooms; all other periods begin with an inventory of rooms that had not reached their use-lives by the end of the previous period. Each period also starts with an arbitrary, provisional, growth rate. Stepping through each year of the period, a room that has reached its use-life in that year is abandoned and a replacement room is built.

Table 3: Modeled growth rate by period for the Heshotauthla survey, 25 years structure use-life.

\begin{tabular}{lrrrrrr} 
Period & Dates & $\begin{array}{c}\text { Observed } \\
\text { Rooms }\end{array}$ & $\begin{array}{c}\text { Period Start } \\
\text { Rooms }\end{array}$ & $\begin{array}{c}\text { Period End } \\
\text { Rooms }\end{array}$ & $\begin{array}{c}\text { Cumulative } \\
\text { Rooms }\end{array}$ & $\begin{array}{c}\text { Growth } \\
\text { Rate (\%) }\end{array}$ \\
\hline A & $850-900$ & 12 & - & - & - & - \\
B & $900-950$ & 38 & 13 & 18 & 38 & 0.7 \\
C & $950-1050$ & 105 & 18 & 36 & 105 & 0.7 \\
D & $1050-1125$ & 97 & 36 & 29 & 97 & -0.3 \\
E & $1125-1175$ & 129 & 29 & 122 & 129 & 2.9 \\
F & $1175-1225$ & 323 & 122 & 208 & 323 & 1.1 \\
G & $1225-1275$ & 468 & 208 & 169 & 468 & -0.4
\end{tabular}




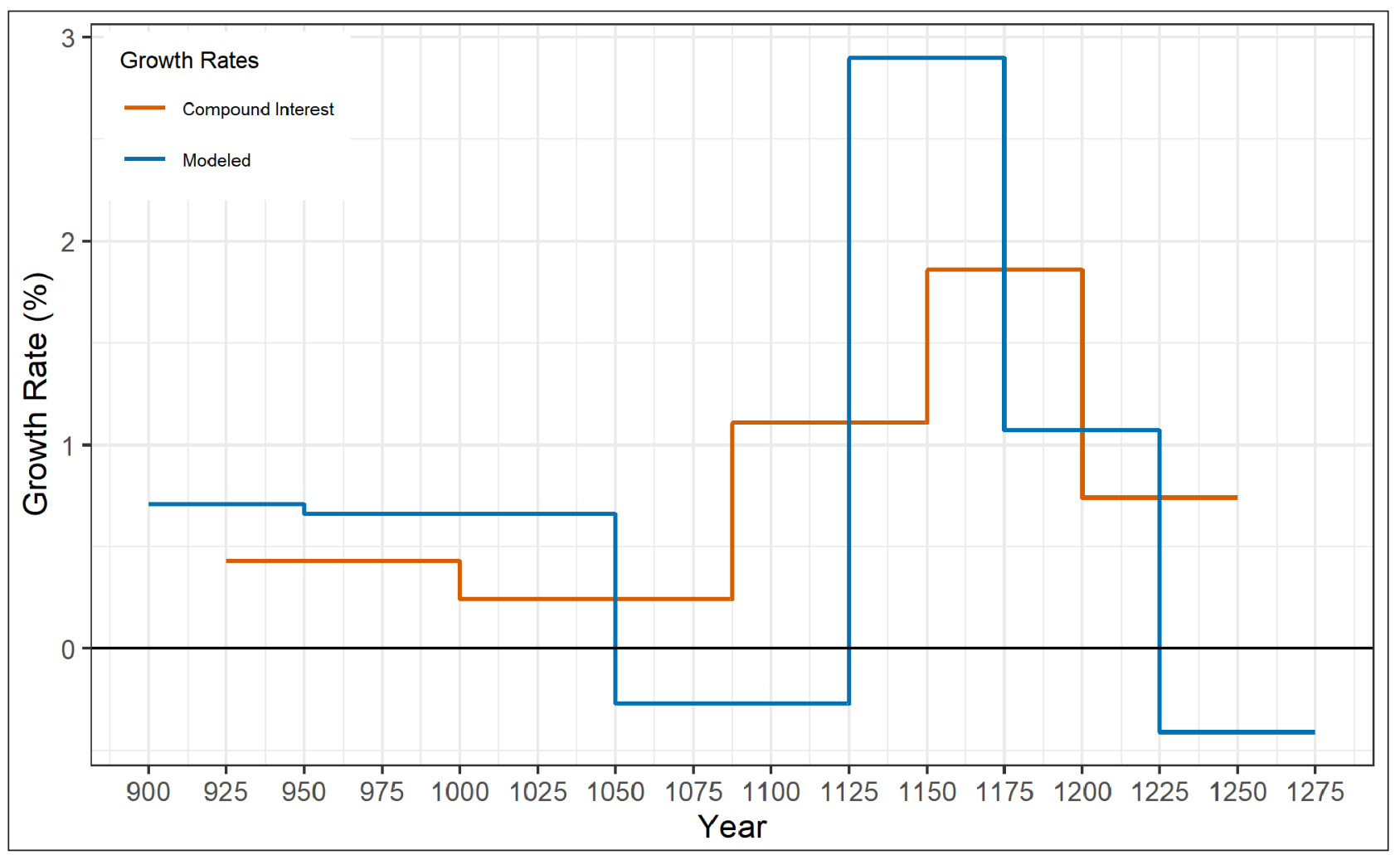

Figure 2: Estimated growth rates for the Heshotauthla survey derived from the formula and the simulation.

The provisional growth rate is then applied to that year to determine if one or more additional rooms need to be constructed (positive growth rate) or abandoned (negative growth rate). Once the final year of a period is reached, the model tabulates the beginning and ending number of rooms for the period, and most importantly, counts the simulated rooms - abandoned or still in use - that are dated to the period. A room whose occupation spans a period boundary is dated to the period with a majority of its occupation. The number of simulated rooms dated to the period is compared to the number of rooms archaeologically observed to date to that period. If they match, then the provisional growth rate is reported as fitting the growth rate for that period. If the observed number of rooms is greater than the modeled number, then the provisional growth rate is increased. If the observed number is lower, then the tentative rate is decreased, and the model is run again, until the room counts match. ${ }^{2}$

More concretely, referring to Table 3, the survey dated 129 rooms to Period E. The model has 29 rooms occupied at the end of Period D that were occupied into Period E. Of these, 15 were built in the previous period but are dated to Period E because more than half their assumed uselife of 25 years was spent in that later period. For each of the 50 years in the Period E, a provisional growth rate is applied to that year's population, starting with the initial population of 29, to determine the number of rooms, if any, that should be constructed or abandoned that year due to population growth or decline. In addition, any room that has been occupied more than 25 years is abandoned and replaced with a new room. At the end of the period, the model yields the number of rooms that would be dated to Period E given the provisional growth rate. If the provisional growth rate produces fewer rooms than observed, the provisional rate is increased; if it produces more than the observed, it is reduced. Iterating through a series of provisional growth rates $(0.00 \%, 1.00 \%$, $2.00 \%, 3.00 \%, 2.90 \%, 2.91 \%, \ldots)$ indicates that an annual growth rate of $2.9 \%$ is required to match the observed 129 rooms dated to Period E. Any substantially lower or higher growth rate will produce a smaller or larger than observed number of rooms dated to that period. The 129 modeled rooms include the 15 rooms already occupied at the beginning of Period E dating to that period (the other 14 beginning rooms are dated to the previous period) and 114 new or replacement rooms built during Period $E$ that also date to that period. In addition, 67 new or replacement rooms are built late enough in Period E to be dated to subsequent period. Using the $2.90 \%$ growth rate, the number of contemporaneously occupied rooms grows from 29 at the beginning to 122 rooms at the end of the period, and these rooms constitute the initial Period $F$ occupation.

\section{Sensitivity Analysis \\ 6.1. Sensitivity to Initial Period Starting Rooms}

In the foregoing discussion we set aside the issue of what the starting number of rooms should be for the initial period, since that cannot be generated by the preceding period. It turns out that the model is, in fact, quite sensitive to the value chosen. Relatively high and relative low values for the initial number of rooms often produce estimated growth rates that oscillate dramatically in successive periods. Choice of a number that is small relative to the total number of rooms dated to the period, results in a high growth rate for the period that in turns results in 
the construction of a large number of rooms near to the end of the period that are dated to the subsequent period. This, in turn, can result in negative growth rate in that next period. Choice of a number that is high relative to the number of dated rooms has the opposite effect.

In the absence of relevant data about the correct value, we suggest basing the selection on the difference between modeled growth rate during each of the initial two periods and the compound interest rate calculated between the first two periods. We recommend using the number of initial rooms that minimizes the larger of the two differences. Employing this guideline with our Heshotauthla data and a 25-year structure use-life, we selected 13 rooms for the initial period. Figure 3 shows that an initial number of rooms in the first period near the selected value has little effect on the growth rates observed, especially after the first two periods. This does suggest however, that the growth rates produced for the first two periods should not be strongly relied upon.

While sensitivity to the initial number of rooms may appear to be a defect of the model, what it really demonstrates is the problem of equifinality of the demographic processes. That is, numerous, quite different possible scenarios could have produced the periodized archaeological record that we face. The compound interest approach does not eliminate this problem, it simply obscures it.

There are two additional startup considerations with the model. First, contrary to what the model assumes, the occupation of the initial period may not start when that period is generally dated to begin. If the occupation were to have started well into that initial period, then the predicted growth rates will be too low and the inventory of rooms beginning the next period will reflect that fact, affecting the growth rates in that second period. In this circumstance there may be relevant external data. For example, if there are deposits that are chronometrically dated early in the period, or if there is evidence of occupation in an earlier period not under consideration, it may be reasonable to assume that there was occupation throughout the period. Indeed, we have omitted period A in our example because we don't know when, within that period, occupation began, and that can have a substantial impact on subsequent periods.

The second has to do with the age distribution of the rooms that are 'constructed' at the beginning the first period under consideration. A cohort of brand-new rooms built at one time may make sense in the case of a major migration into the area, but if there is evidence of occupation prior to the initial period under consideration, as is the case here, it makes sense to randomly age the rooms between 0 years and their use life. This choice is given the user, but the randomized ages are used in the analyses presented here.

\subsection{Sensitivity to Structure Use-life}

In Table 3 and the example presented above, we use a structure use-life of 25 years, which seems reasonable for the pueblo occupations under consideration. Relying mainly on Ahlstrom (1985), Kintigh, Glowacki and Huntley (2004: 443) provide a detailed discussion of this choice. While 25 years seems reasonable and has some empirical support, we are by no means certain that is, in fact, a good value. We need to know how sensitive our results are to this choice. Thus, using the model, we explore the results with use-lives of $15,20,25$, and 30 years.

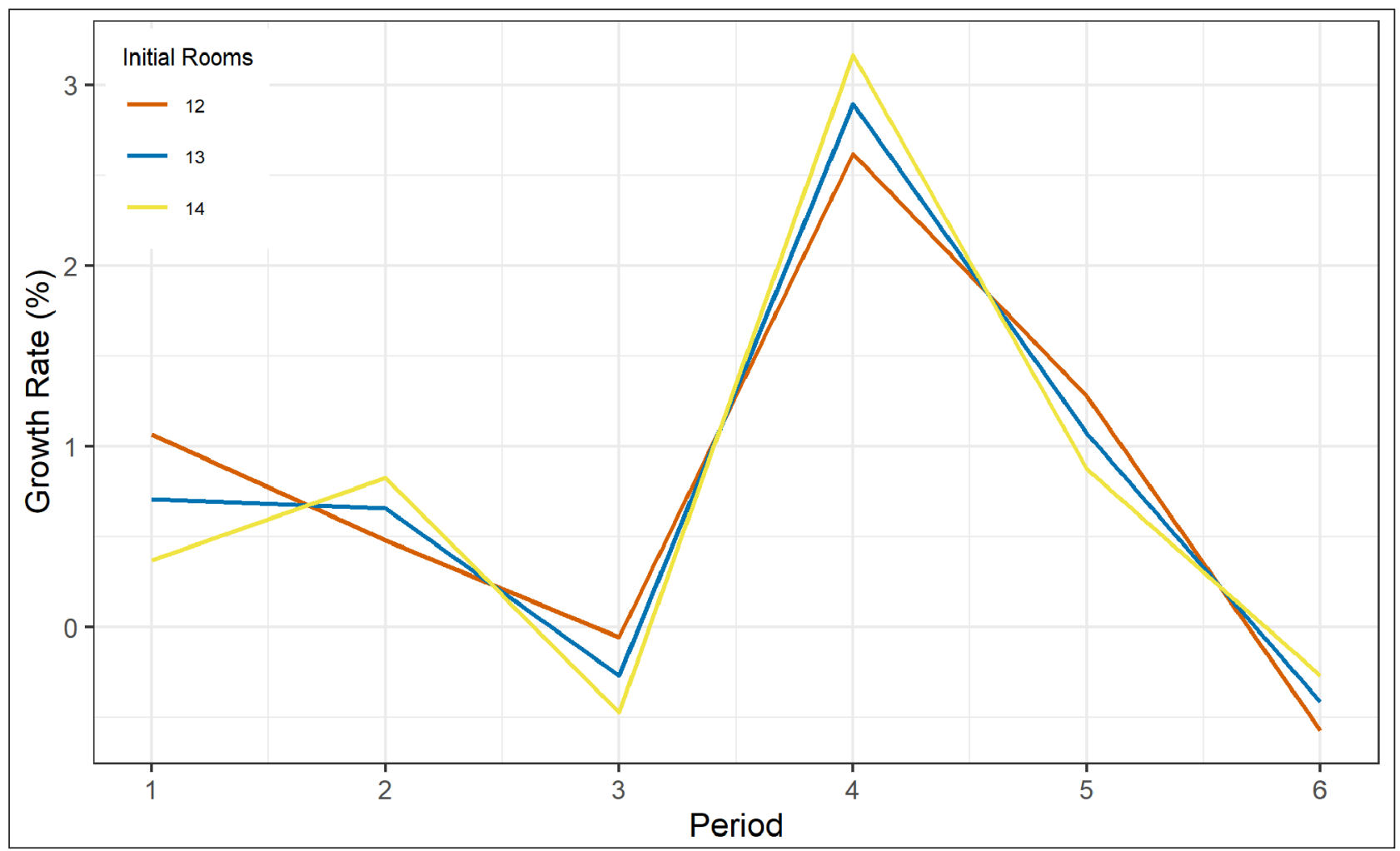

Figure 3: Sensitivity to the number of initial rooms, Heshotauthla survey. 
As long as we select numbers of initial period rooms as described above, Figure 4 shows that the choice of different values for the structure use life affects the absolute growth rates but that the patterns of growth and decline are generally preserved.

The model, as now implemented, not only allows the user to stipulate a fixed structure use-life, but also allows the user to assign a normal (Gaussian) distribution for the use-life with a user-specified mean use-life and standard deviation, with modeled use-life truncated to have a minimum of one year and a maximum of twice the mean uselife. Figure $\mathbf{5}$ shows that results obtained with Normally distributed structure use-lives follow closely with the fixed (S.D. $=0)$ use-life.

\section{Heshotauthla Results}

Thus far, we have focused mainly on the mechanics of the modeled and compound interest approaches to estimating population growth. Referring back to Figure 2, the two approaches clearly yield substantially different results, both of which are consistent with the archaeological room counts by period. However, if we look at the numbers of occupied rooms through time predicted by the two approaches, the differences are less dra-

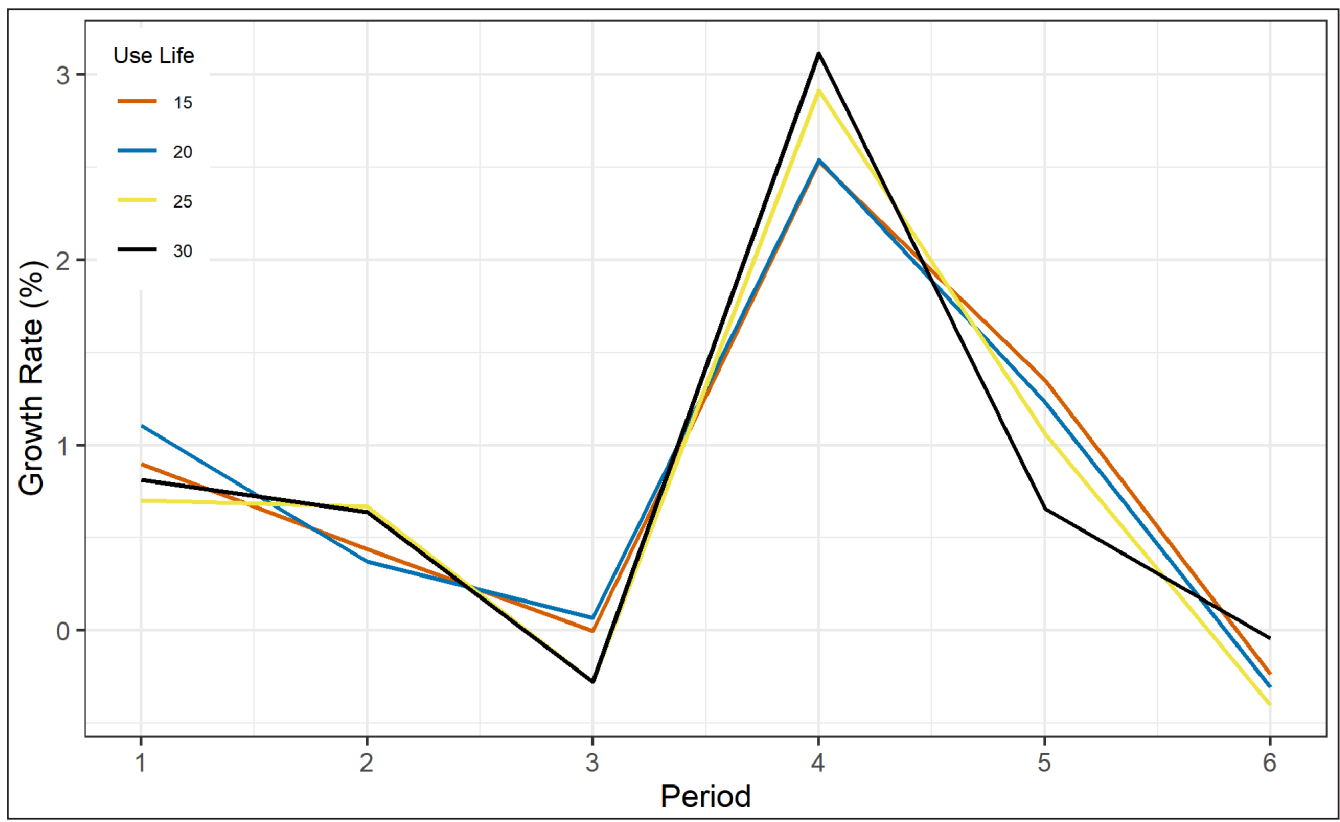

Figure 4: Sensitivity to room use-life, Heshotauthla survey.

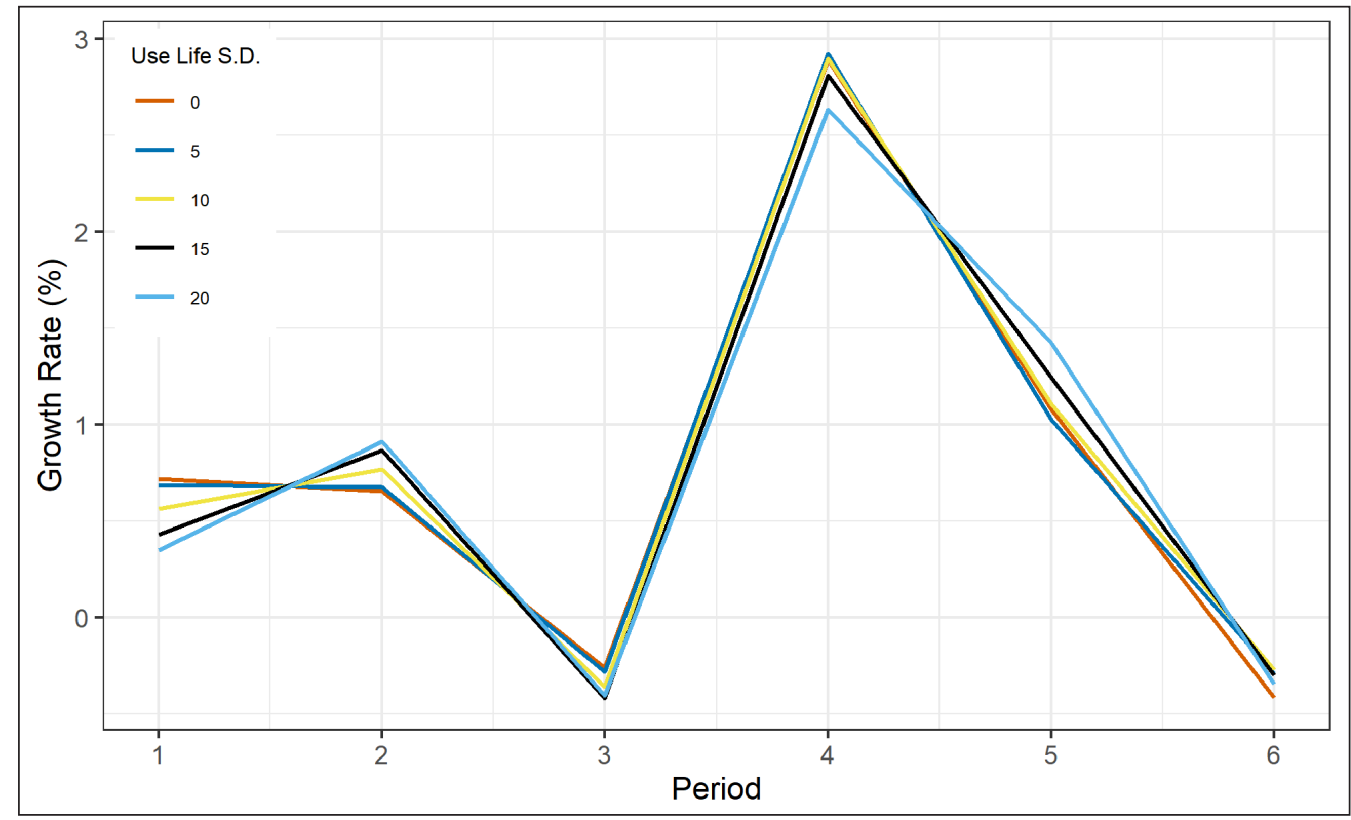

Figure 5: Modeled growth rates using normally distributed structure use lives with mean of 25 years and different standard deviations (standard deviation of 0 is a fixed structure use life). The red, S.D. $=0$ line is very close to the dark blue, std $=5$ line. 
matic than might be expected. The modeling approach directly generates a number of occupied rooms in each year. With the compound interest approach, we can derive comparable numbers by starting with the number of rooms per 25 years at the midpoint of period 1 and applying the compound interest growth rate, year by year. Figure 6 shows that through most of this interval, these curves are similar, both showing sharp rises starting between $A D 1125$ and 1150. The key difference is that the modeling approach shows a substantial decline in population starting about 1225 while the compound interest approach shows a continued increase. As noted above, this seems sensible given the establishment at that time, nearby, of the 800 room Heshotauthla pueblo, which absorbed all of the population of the survey area by about 1300 . This pattern also mirrors regional trends in population (Peeples and Schachner 2012) and detailed seriations for the area around Heshotauthla, including the survey area considered here, which show population decline starting by the mid-thirteenth century (Peeples and Schachner 2012).

\section{Ojo Bonito Survey}

The survey of the Ojo Bonito area on the Hinkson Ranch immediately south of the Zuni Indian Reservation serves as our second example. This full coverage survey of 57.6 $\mathrm{km}^{2}$, conducted between 1984 and 1994, recorded 560 archaeological sites, not all of which were prehistoric habitation sites. Similar to the Heshotauthla survey, sites were assigned to chronological periods based on the ceramic complexes represented in their surface assemblages. Table 4 displays the room counts by period.
The Ojo Bonito and Heshotauthla growth rate and population curves have similar shapes (Figures $\mathbf{7}$ and $\mathbf{2}$ ). However, in the Ojo Bonito case, both the first interval of negative growth and the peak growth rate occur later in time and are more dramatic, and the terminal decline in growth rate is more pronounced. Comparing Figures 6 and $\mathbf{8}$, at Ojo Bonito, the simulated population curve differs more substantially from the population curve based on the compound interest approach than it does at Heshotauthla. Notably, Peeples and Schachner (2012) also suggested a decline in the number of occupied rooms and sites in the Ojo Bonito beginning in the early thirteenth century, based on a detailed seriation analysis that split sites into individual components where possible. In that analysis, the population curves of the Ojo Bonito and Heshotauthla areas were also quite similar and the decline in population also began earlier in the Ojo Bonito area. This suggests that the best available information for dating settlements and rooms for the region is more in line with the results of the modeled population rather than the simple growth rate formula.

Table 4: Room counts by period, Ojo Bonito survey.

\begin{tabular}{lcrr} 
Period & Dates & Rooms & Rooms/25 Years \\
\hline C & $1000-1050$ & 82 & 41.0 \\
D & $1050-1125$ & 154 & 51.3 \\
E & $1125-1175$ & 77 & 38.5 \\
F & $1175-1225$ & 244 & 122.0 \\
G & $1225-1275$ & 574 & 287.0
\end{tabular}

Figure 6: Number of occupied rooms through time for the Heshotauthla survey, computed annually for the simulation and using the compound interest formula. 




Figure 7: Estimated growth rates for the Ojo Bonito survey derived from the formula (red line) and the simulation (blue line).

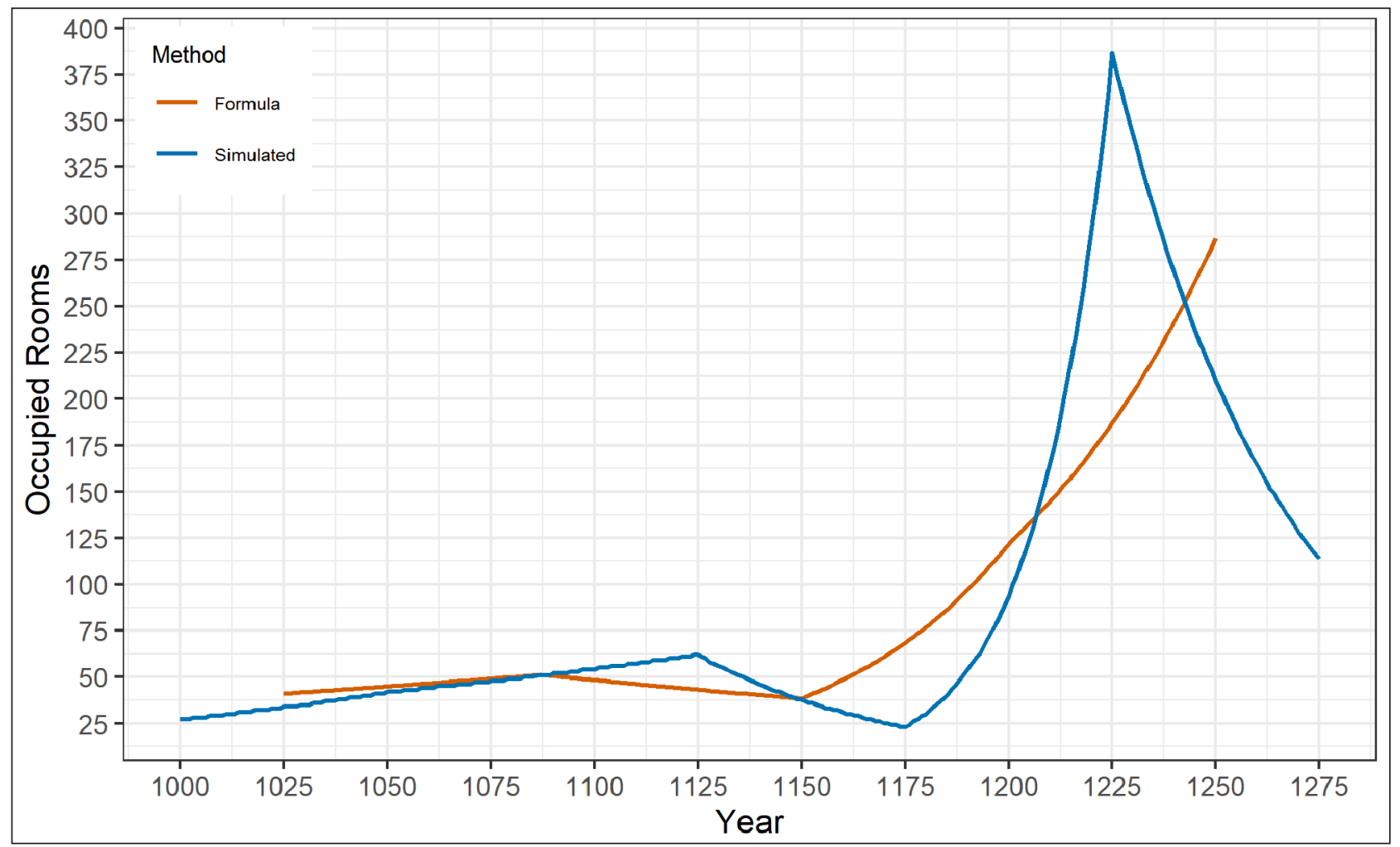

Figure 8: Number of occupied rooms through time for the Ojo Bonito survey, computed annually by the simulation and using the compound interest formula.

\section{The Mimbres Survey}

Blake, LeBlanc and Minnis' (1986) influential publication of the Mimbres Foundation's survey of the Mimbres Valley approaches many of the questions attacked here. The article is based on extensive data and does an admirable job of not only presenting their source data and results but also explaining their assumptions and methods. It is useful to revisit their work in light of the discussion in 
the paper, to see what additional or different conclusions might be drawn.

The original paper can be consulted for more detail, but we note that the Mimbres Foundation systematically surveyed a stratified sample of about $11 \%\left(100 \mathrm{~km}^{2}\right)$ of the $903 \mathrm{~km}^{2}$ Mimbres Valley and reported room counts where possible and room area, in five periods from AD 200 to about 1400 . Based on the by-stratum sampling fraction, they extrapolate the room counts and room area to the entire valley as presented in Table $\mathbf{5}$.

They assume a constant growth rate though out the entire sequence, which they calculate using the compound interest formula, using data from the two best understood periods. For their sample survey of the Mimbres area, Blake, LeBlanc and Minnis (1986: 454) used occupied room area by period to calculate a growth rate from the Late Pithouse period (AD 550-1000; 23,151 $\mathrm{m}^{2}$ ) through the Classic Period (AD 1000-1150; 80,405 $\mathrm{m}^{2}$ ). They use the Early Pithouse period (AD 200-550; $12,904 \mathrm{~m}^{2}$ ) room area as the initial area for the Late Pithouse Period and the Classic Period room area as the terminal area calculate the rate over the entire 600 years of the Late Pithouse and Classic Periods, yielding a rate of $(80405 / 12904)^{1 / 600}=0.31 \%$. Had they used their standardized room area $^{3}$ and the temporal midpoints for the Early Pithouse (2718 $\left.\mathrm{m}^{2} ; \mathrm{AD} 375\right)$ and Classic Period $\left(40,203 \mathrm{~m}^{2} ; \mathrm{AD} 1075\right)$ they would have gotten a similar rate of $(40,203 / 2718) 1 / 700=0.39 \%$. Assuming the $0.3 \%$ growth rate throughout the sequence, they then explored the implications of different structure use life on population, with little consideration of the possibility that the growth rates were not constant.

Using the model proposed here, we can use their data to ask what the within-period growth rates might have been. The model provides very similar results for growth rates for use-lives of $15,20,25$, and 75 years (75 is the number used by Blake and his colleagues, page 453-454).

Table 5: Mimbres Valley data from Blake, LeBlanc and Minnis (1986) tables 4-6 and 8-104.

\begin{tabular}{lrrr} 
Period & \multicolumn{1}{c}{ Dates } & Rooms & Rooms/75 Years \\
\hline Early Pithouse & $200-550$ & 646 & 138.4 \\
Late Pithouse & $550-1000$ & 1215 & 202.5 \\
Classic & $1000-1150$ & 4848 & 2424.0 \\
Black Mountain & $1150-1275$ & 560 & 336.0 \\
Cliff & $1275-1350$ & 286 & 286.0
\end{tabular}

Recalling that we set the initial number of rooms for the first period to minimize the difference between the growth rate for the first two periods and the compound interest growth rate between those periods (Table 6), for all use-lives we get the first two period growth rates between $0.09 \%$ and $0.12 \%$, very close to the formula's $0.10 \%$, and a Classic period growth rate of $2.4 \%$ to $2.5 \%$. However, at this point, the model breaks down because the number of rooms built late in the Classic period and therefore dated to the Black Mountain phase is more than the number of total rooms dated to the Black Mountain phase. This indicates a discontinuity in the sequence - in which the occupation is not continuous between adjacent periods - thereby violating the assumptions of the model.

If we rerun the model for the Early Pithouse Period through the Classic Period (this is similar to the approach taken by Blake and his colleagues), the model dates all the rooms in the terminal period to that period, rather than assuming that late-constructed rooms will have assemblages dating to the subsequent period (Table 7). This observation more closely fits the archaeological record for the Mimbres Valley than an assumption of continuity into the Black Mountain phase. Running the model for the three periods, the modeled growth rates near $0.1 \%$ for the first two periods of course do not change, but the Classic period growth rate is reduced to about $2.2 \%$ for structure use-lives from 15 to 25 years, and to 2.1 to $1.8 \%$ for uselives from 30 to 75 years.

We suggest that a low growth rate on the order of $0.1 \%$ during the Early and Late Pithouse periods, rapid growth of about $2 \%$ in the Classic, followed by a discontinuity and depopulation in the Black Mountain and Cliff phase provides a more refined, and more useful and accurate characterization of what happened in the Mimbres than a steady growth rate of $0.3 \%$ to $0.4 \%$ throughout the Early Pithouse through Classic periods.

Table 6: Period-to-period growth rate using compound interest formula.

\begin{tabular}{lrr} 
Interval & \multicolumn{1}{c}{$\begin{array}{c}\text { Growth } \\
\text { Rate r (\%) }\end{array}$} \\
\hline EPH - LPH & $375-775$ & 0.10 \\
LPH - Classic & $775-1075$ & 0.83 \\
Classic - Black Mountain & $1075-1213$ & -1.43 \\
Black Mtn - Cliff & $1213-1313$ & -0.16
\end{tabular}

Table 7: Simulated growth rates for the Mimbres Valley.

\begin{tabular}{lrrrrr} 
& \multicolumn{5}{c}{ Use Life } \\
\cline { 2 - 6 } & \multicolumn{1}{c}{ Dates } & 15 years & 25 years & 30 years & 75 years \\
\hline Early Pithouse & $200-550$ & 0.09 & 0.11 & 0.12 & 0.12 \\
Late Pithouse & $550-1000$ & 0.10 & 0.10 & 0.11 & 0.11 \\
Classic & $1000-1150$ & 2.25 & 2.16 & 2.12 & 1.80
\end{tabular}




\section{Improving Estimates for Demographic Rates}

Given the interpretive value of accurate assessments of population dynamics, what steps might be taken to improve those estimates for survey data? For either approach discussed here, the most useful improvement would be more refined dating that allow temporal assignments to shorter time periods and better dating of the initial occupation of an area. Seriations that position site occupations within periods would allow demographic reconstructions that do not assume constant growth rates over substantial temporal intervals would be even more helpful (e.g., Peeples and Schachner 2012). Better understanding of structure occupation span and use-life and their variability would improve application of the modeling approach.

\section{Conclusions}

Reconstructing the dynamics of past populations is a task central to understanding numerous social processes from migrations, to population aggregation, to changes in social complexity. Systematic settlement surveys provide some of the best archaeological data for that purpose (Drennan, Berrey and Peterson 2015). This article focuses on estimating rates of population growth and decline using house or room counts or proxies for them from systematic surveys in which rooms or houses are dated to one of a sequence of chronological periods, but with no temporal resolution within periods.

In archaeology, one approach to this problem has been to use a compound interest formula and standardized room counts by period to calculate growth rates between adjacent periods. In contrast, we propose a method that models the construction and abandonment of rooms to derive a within-period growth rate that yields a simulated total of dated rooms that matches the empirical observation of the number of rooms dated to that period.

As we have shown, the approaches can yield substantially different results with quite different implications for the underlying social processes. The simulation makes a number of explicit, simplifying assumptions, any of which may be unrealistic in a given circumstance. However, application of the formula to the same data also entails acceptance of assumptions, though they often remain inexplicit and unexplored. We suggest that while they may be easier to ignore, in fact they may be more problematic than those of the simulation.

The question is not which approach provides the correct answer. It is almost unimaginable that the assumptions of either approach are realistic, notably that of a constant growth rate within [simulation] or between [formula] lengthy archaeological periods. Instead, we need to ask to what extent they can inform us about the broad outlines of past population dynamics.

The first, and we believe unarguable, conclusion is that there is an enormous problem of equifinality in the reconstruction of population dynamics. There are countless plausible and quite different scenarios that can result in exactly the same set of observed data-the room counts by period. Unfortunately, additional evidence that would allow us to discriminate among the alternatives will often be lacking.

Certainly, the equifinality problem indicates that we should not take any result as gospel. Instead, we need to evaluate the assumptions that underlie the results and the sensitivity of the results to changes in assumptions. While we recommend maintaining a healthy skepticism, we believe that in many cases the simulation approach relies on assumptions that are more plausible and will yield results that are superior to those produced by the formula. Based on our knowledge of the archaeology of these areas, this certainly appears to be so for the cases presented here.

\section{Data Accessibility Statement}

All data (room counts by period) needed to reproduce these results are provided in tables in this article, some of which are derived from data presented by Blake, LeBlanc and Minnis (1986). The simulation is implemented in a program written in the Pascal language. Pascal is a strongly typed, procedural, compiled language that fosters highly readable and maintainable code and is also very fast and memory efficient. The program has about 800 lines of dedicated code in addition to employing system and user-developed library procedures. It was developed in Embarcadero's Delphi environment but could be compiled with little or no modification in Free Pascal. The program was run in a Windows environment but can be compiled for Mac or Linux systems. The source and compiled Windows code, program documentation, $R$ code and program output that produced the figures, and copies of the data sets on which the program was run are available on Github at https://github.com/kintigh/RoomAccum.

\section{Notes}

${ }^{1}$ Hassan (1978: 69 and 1981: 139-140) offers a different formula also used by Blake, LeBlanc and Minnis (1986): $r_{12}=(1 / t) \ln \left(p_{2} / p_{1}\right)$. The two formulae provide values for $r$ that are within $0.1 \%$ of each other for except for very high rates of population growth or decline $(|r|>4.5 \%)$.

${ }^{2}$ In this example, obtaining a match required between 8 and 15 trials. Because room counts are integers a limited range of growth rates will produce the same results.

${ }^{3}$ Blake, LeBlanc and Minnis (1986) standardized by dividing by the shortest period length; the effect on population and population growth estimates is the same.

${ }^{4}$ We use the adjusted number of rooms for the Classic period from their Table 6 . We use the period dates for the Black Mountain and Cliff Phases implied by a start of the sequence at AD 200 and the period lengths in their Table 10. These dates do not match the period dates provide in their textual descriptions on page 442 .

\section{Acknowledgements}

An earlier version of the approach presented here was used in Kintigh, Glowacki and Huntley (2004). It was developed further in the authors' presentation at the 2007 Annual 
Meeting of the Society for American Archaeology in a session organized by Margaret Nelson and Cathy Cameron: Demographic, Social, and Ideological Perspectives on Population Movement: Papers in Honor of Linda S. Cordell. The version presented here is the result of considerable additional development. The authors are grateful to the Pueblo of Zuni Tribal Council for permitting the Heshotauthla survey and to the Zuni individuals whose grazing areas we were allowed to investigate. Similarly, we are grateful to the late Mrs. Everett Hinkson who permitted and encouraged the Ojo Bonito Survey on her ranch. The Heshotauthla and Ojo Bonito surveys were accomplished, over several field seasons, by graduate and undergraduate students participating in the Arizona State University Summer Archaeological Field School. In particular, we recognize the efforts of Andrew Duff, Eric Angstadt-Leto, Blas Castellon, Suzanne Eckert, and Nancy Mahoney in leading survey teams and Suzanne Eckert for her expert analyses of the ceramic collections that permitted the high-resolution dating that we have for the Heshotauthla and Ojo Bonito area sites. We gratefully acknowledge the helpful comments of two anonymous reviewers.

\section{Competing Interests}

The authors have no competing interests to declare.

\section{References}

Ahlstrom, RVN. 1985. The interpretation of archaeological tree-ring dates. Unpublished thesis (Ph.D). Tucson: University of Arizona.

Ammerman, AJ. 1981. Surveys and archaeological research. Annual Review of Anthropology, 10: 63-88. DOI: https://doi.org/10.1146/annurev. an.10.100181.000431

Blake, M, LeBlanc, SA and Minnis, PE. 1986. Changing settlement and population in the Mimbres Valley, SW New Mexico. Journal of Field Archaeology, 13(4): 439-464. DOI: https://doi.org/10.1179/ jfa.1986.13.4.439

Cameron, CM. 1999. Hopi dwellings: architectural change at Orayvi. Tucson: University of Arizona Press.

Chamberlain, A. 2006. Demography in archaeology. Cambridge: Cambridge University Press. DOI: https://doi.org/10.1017/CBO978051-1607165

Cowgill, GL. 1975. On the causes and consequences of ancient and modern population changes. American Anthropologist, 77: 505-575. DOI: https://doi. org/10.1525/aa.1975.77.3.02a00030

Dewar, RE. 1991. Incorporating variation in occupation span into settlement-pattern analysis. American Antiquity, 56(4): 604-620. DOI: https://doi. org/10.2307/281539

Drennan, RD, Berrey, CA and Peterson, CE. 2015. Regional settlement demography in archaeology. Clinton Corners, NY: Elliott Werner. DOI: https:// doi.org/10.2307/j.ctvqc6hgm

Flannery, KV. 2002. The origins of the village revisited: from nuclear to extended households. American Antiquity, 67(3): 417-433. DOI: https://doi. org/10.2307/1593820
Hassan, FA. 1978. Demographic archaeology. Advances in Archaeological Method and Theory, 1: 49-103. DOI: https://doi.org/10.1016/ B978-0-12-003101-6.50009-3

Hassan, FA. 1981. Demographic archaeology. New York: Academic Press. DOI: https://doi.org/10.1016/ B978-0-12-624180-8.50010-X

Hill, JB, Clark, JJ, Doelle, WH and Lyons, PD. 2004. Prehistoric demography in the Southwest: migration, coalescence, and Hohokam population decline. American Antiquity, 69(4): 689-716. DOI: https:// doi.org/10.2307/4128444

James, SR. 1997. Change and continuity in Western Pueblo households during the historic period in the American Southwest. World Archaeology, 28(3): 429-456. DOI: https://doi.org/10.1080/00438243 .1997 .9980357

Kintigh, KW. 1994. Contending with contemporaneity in settlement-pattern studies. American Antiquity, 59(1): 143-148. DOI: https://doi. org/10.2307/3085507

Kintigh, KW, Glowacki, DM and Huntley, DL. 2004. Long-term settlement history and the emergence of towns in the Zuni area. American Antiquity, 69(3): 432-456. DOI: https://doi.org/10.2307/4128401

Mills, BJ, Peeples, MA, Aragon, LD, Bellorado, BA, Clark, JJ, Giomi, E and Windes, TC. 2018. Evaluating Chaco migration scenarios using dynamic social network analysis. Antiquity, 92(364): 922-939. DOI: https://doi.org/10.15184/aqy.2018.86

Mindeleff, V. 1891. A study of pueblo architecture in Tusayan and Cibola. Eighth Annual Report of the Bureau of American Ethnology. Washington, DC: Smithsonian Institution.

Ortman, SG. 2016. Uniform probability density analysis and population history in the northern Rio Grande. Journal of Archaeological Method and Theory, 23(1): 95-126. DOI: https://doi. org/10.1007/s 10816-014-9227-6

Ortman, SG, Varien, MD and Gripp, TL. 2007. Empirical Bayesian methods for archaeological survey data: an application from the Mesa Verde region. American Antiquity, 72(2): 241-272. DOI: https:// doi.org/10.2307/40035813

Peeples, MA. 2018. Connected communities: networks, identities, and social change in the ancient Cibola world. Tucson: University of Arizona Press. DOI: https://doi.org/10.2307/j.ctt1ws7wrq

Peeples, MA and Schachner, G. 2012. Refining correspondence analysis-based ceramic seriation of regional data sets. Journal of Archaeological Science, 39(8): 2818-2827. DOI: https://doi.org/10.1016/j. jas.2012.04.040

Petrie, CA and Lynam, F. 2020. Revisiting settlement contemporaneity and exploring stability and instability: case studies from the Indus civilization. Journal of Field Archaeology, 45(1): 1-15. DOI: https://doi.org /10.1080/00934690.2019.1664848

Schacht, RM. 1981. Estimating past population trends. Annual Review of Anthropology, 10: 
119-140. DOI: https://doi.org/10.1146/annurev. an.10.100181.001003

Schreiber, KJ and Kintigh, KW. 1996. A test of the relationship between site size and population. American Antiquity, 61(3): 573-579. DOI: https:// doi.org/10.2307/281841

Steadman, SR. 2016. Archaeology of domestic architecture and the human use of space. London and New York: Routledge. DOI: https://doi. org/10.4324/9781315433974

Thompson, MS. 2012. The use history of small roomblocks in pueblo iii period settlement clusters of the El Morro Valley, New Mexico. Kiva, 78(1): 9-36. DOI: https://doi.org/10.1179/kiv.2012. 78.1 .9
Varien, MD and Mills, BJ. 1997. Accumulations research: problems and prospects for estimating site occupation span. Journal of Archaeological Method and Theory, 4(2): 141-191. DOI: https://doi. org/10.1007/BF02428057

Willey, GR. 1956. The Structure of ancient Maya society: evidence from the southern lowlands. American Anthropologist, 58(5): 777-782. DOI: https://doi. org/10.1525/aa.1956.58.5.02a00020

Wilshusen, RH. 2002. Estimating population in the central Mesa Verde region. In: Varien, MD and Wilshusen, RH (eds.), Seeking the center place: archaeology and ancient communities in the Mesa Verde region, 101-120. Salt Lake City: University of Utah Press.

How to cite this article: Kintigh, KW and Peeples, MA. 2020. Estimating Population Growth Rates and Instantaneous Population from Periodized Settlement Data. Journal of Computer Applications in Archaeology, 3(1), pp. 197-209. DOl: https://doi.org/10.5334/ jcaa. 58

Submitted: 02 April $2020 \quad$ Accepted: 08 June $2020 \quad$ Published: 02 July 2020

Copyright: (c) 2020 The Author(s). This is an open-access article distributed under the terms of the Creative Commons Attribution 4.0 International License (CC-BY 4.0), which permits unrestricted use, distribution, and reproduction in any medium, provided the original author and source are credited. See http://creativecommons.org/licenses/by/4.0/. 